\title{
In vitro studies on crystallization of SeMHP and strategies for nucleation reduction
}

\author{
G KANCHANA ${ }^{\dagger}$, P SUNDARAMOORTHI* and G P JEYANTHI \\ Department of Physics, Thiruvalluvar Govt. Arts College, Namakkal 637 401, India \\ ${ }^{\dagger}$ Department of Biochemistry, Avinashilingam University for Women, Coimbatore 641 043, India
}

MS received 13 April 2008; revised 3 June 2008

\begin{abstract}
Naturally many types of crystals grow in our human body. Especially different crystals or minerals are deposited in human urinary tracts. These crystals are named as octacalcium phosphate (OCP), calcium hydrogen phosphate (CHP), hydroxyapatite (HAP), magnesium hydrogen phosphate (MHP) etc. The SeMg$\mathrm{HPO}_{4}$ crystals are also known as Selenio-Newberryite crystals. The main reasons for the formation of crystals are due to the increased concentration of magnesium and phosphate ions in the human urine. In the present study, SeMHP crystals are grown in silica gel medium at various concentrations and different $\mathrm{pH}$ values in sun light medium and laser exposed medium. It has been observed that the nucleation rate was partially and completely reduced in sunlight and laser exposed medium, respectively. During the growth period, Liesegang rings were observed. Characteristic studies of SeMHP crystals such as FTIR, AAS, SEM, XRD, TGA/DTA and etching were done. The results are compared with the reported values and discussed in detail.
\end{abstract}

Keywords. Inorganic compounds; crystal growth; sol-gel chemistry; thermogravimetric analysis; crystal structure.

\section{Introduction}

In the modern world, the growth of high quality single crystal plays an important role in pharmaceutical, organic and chemical industries etc. Artificial crystal growth is important to identify the properties of the material and provides information about the structure, composition and physico-chemical properties of the grown crystals.

Lots of minerals are present in all living mammal's body at different degrees of concentration. When the body fluid gets supersaturated, crystallization (Dieppe and Calver 1986) takes place automatically which have beneficial as well as pathological effect in the human body. The beneficial role of crystallization is bone and teeth formation, which contains micro crystals of hydroxyapatite, and helps in our sense of balance and dynamic nature i.e. depends on small calcite crystal present in the inner ear. Kidney stone (KS) or renal stone (RS), is one of the pathological effects of crystallization and is a huge painful urological disease (Arthure and Obst 1953; Sutor 1989; Hess and Kok 1996). The urinary tract or system consists of kidneys, ureters, bladder and urethra. Kidney removes extra water and waste from the blood in the form of urine. Kidney helps to maintain the normal mineral contents of the blood. Naturally, urine has some chemi-

\footnotetext{
*Author for correspondence (moorthi.sundara@gmail,com)
}

cals known as inhibitor that restrict the crystal formation. Increase in mineral value decreases the level of inhibitors thereby leading to stone formation (Henisch 1988). If the size of crystal is too small, it will travel through the urinary tract and excreted in urine without pain or notice. If the stone size is large, it produces a lot of pain and side effects. Kidney stones are made of varying chemical compositions. Generally it contains magnesium and calcium in combination with either oxalate or phosphate. The kidney stone occurs most frequently in men compared to women and it occurs in the age group of 20 to 50 years (Alexander and Honson 1949; Eitel 1954; Gilman 1958; Yean et al 1961; Henisch et al 1965; Corns 1983). Selenium magnesium hydrogen phosphate crystal belongs to one of the kidney stone compositions. These crystals are grown artificially by single diffusion method.

\section{Experimental}

Selenium magnesium hydrogen phosphate crystals are grown by single diffusion method. The silica gel, also known as water glass, was used in the present work as an intermediate growth medium. SMS (AR-sodium meta silicate powder) was added to the double distilled water in the ratio of $1: 1$, mixed and stirred well and kept undisturbed for a few days to allow sedimentation. Then the clear top solution was filtered and stored in a light protected glass container. This is known as a stock solution. 
Table 1. Growth parameters of SeMHP crystals.

\begin{tabular}{|c|c|c|c|c|c|c|c|}
\hline $\begin{array}{l}\text { SMS gel } \\
\text { density } \\
(\mathrm{g} / \mathrm{cc})\end{array}$ & $\begin{array}{c}\text { OPA } \\
\text { concentration } \\
\text { (N) }\end{array}$ & $\begin{array}{c}\mathrm{Gel}+\mathrm{H}_{3} \mathrm{PO}_{4} \\
\mathrm{pH} \text { value }\end{array}$ & $\begin{array}{l}\text { Gel setting } \\
\text { time }(\mathrm{h})\end{array}$ & $\begin{array}{c}\text { Supernatant } \\
\text { concentration } \\
\mathrm{ZnSe}+\mathrm{MgCl}_{2}(\mathrm{M})\end{array}$ & $\begin{array}{l}\text { Nucleation } \\
\text { observed (h) }\end{array}$ & $\begin{array}{l}\text { Growth period } \\
\quad \text { (days) }\end{array}$ & $\begin{array}{c}\text { Types of crystal } \\
\text { observed/harvested } \\
\text { crystal size }\end{array}$ \\
\hline \multirow[t]{2}{*}{$1 \cdot 04$} & $0 \cdot 5$ & $\begin{array}{l}6 \cdot 5 \\
6 \cdot 9 \\
7 \cdot 2\end{array}$ & $\begin{array}{r}24 \\
1 \\
34\end{array}$ & $\begin{array}{l}1: 1 \\
- \text { do- } \\
\text {-do- }\end{array}$ & $\begin{array}{r}16 \\
20 \\
100\end{array}$ & 70 & Many poly crystals \\
\hline & 1 & $\begin{array}{l}6 \cdot 5 \\
7 \cdot 0 \\
7 \cdot 5\end{array}$ & $\begin{array}{r}14 \\
1 \\
28\end{array}$ & $\begin{array}{l}\text {-do- } \\
\text {-do- } \\
\text {-do- }\end{array}$ & $\begin{array}{l}10 \\
06 \\
64\end{array}$ & 80 & Dendrite crystals \\
\hline \multirow[t]{2}{*}{1.05} & $0 \cdot 5$ & $\begin{array}{l}6 \cdot 4 \\
6 \cdot 9 \\
7 \cdot 3\end{array}$ & $\begin{array}{l}34 \\
16 \\
48\end{array}$ & $\begin{array}{l}\text {-do- } \\
\text {-do- } \\
\text {-do- }\end{array}$ & $\begin{array}{l}10 \\
12 \\
38\end{array}$ & 60 & $\begin{array}{l}\text { Liesegang rings are } \\
\text { observed }\end{array}$ \\
\hline & 1 & $\begin{array}{l}6 \cdot 5 \\
6 \cdot 8 \\
7 \cdot 3\end{array}$ & $\begin{array}{r}16 \\
1 \\
24\end{array}$ & $\begin{array}{l}\text {-do- } \\
\text {-do- } \\
\text {-do- }\end{array}$ & $\begin{array}{l}24 \\
10 \\
64\end{array}$ & 65 & Single crystals \\
\hline
\end{tabular}

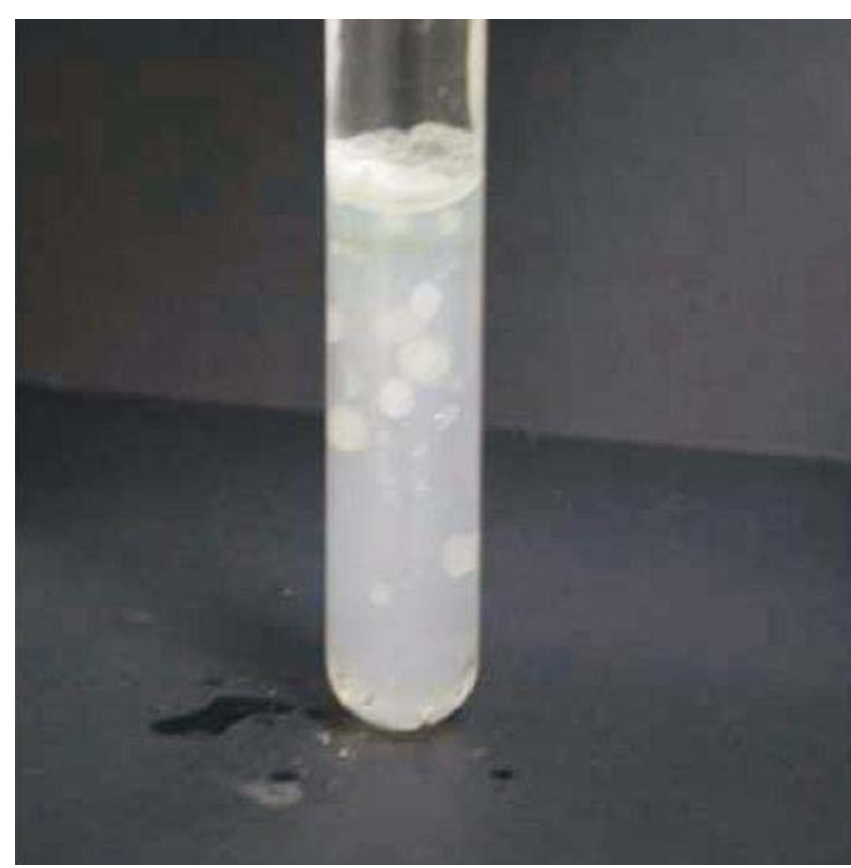

Figure 1. Growth of SeMHP crystal within laboratory environment (SDP).

The gel densities of 1.04 and $1.05 \mathrm{~g} / \mathrm{cc}$ were used. Simple test tubes of $25 \mathrm{~mm}$ diameter and $150 \mathrm{~mm}$ length were used. The concentrations of orthophosphoric acid used in the experiments were $0.5 \mathrm{~N}$ and $1 \mathrm{~N}$ and the concentration of supernatant solution $\left(\mathrm{ZnSe}+\mathrm{MgCl}_{2}\right)$ varied from $0.5 \mathrm{M}$ to $2 \mathrm{M}$ (Alexander 1949; Eitel 1954). One of the reactants, orthophosphoric acid, was mixed within the gel solution. The gel solution was taken as one third of its volume of the test tubes and after the gel set, the supernatant solution was added slowly along the sides of the test tubes. $\mathrm{ZnSe}+\mathrm{MgCl}_{2}$ diffused through the gel medium, which contained orthophosphoric acid. The chemical reaction took place which led to the growth of $\mathrm{SeMgHPO}_{4}$ crystal (Sundaramoorthi et al 2007a, b).

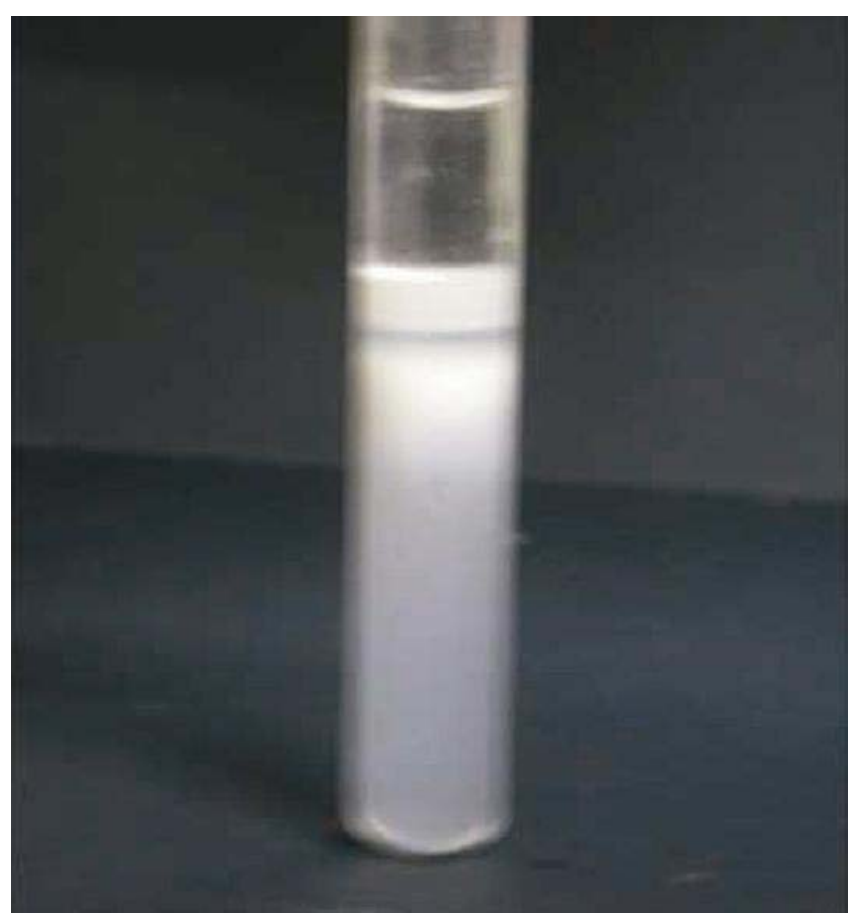

Figure 2. Growth of SeMHP crystal SDP within the sunlight exposed medium.

The chemical reaction was

$$
\begin{array}{r}
\mathrm{Se}^{2+}+\mathrm{Mg}^{2+}+\mathrm{HPO}_{4}^{2-}+2 \mathrm{H}_{2} \mathrm{O} \rightarrow \underset{\mathrm{SeMgHPO}}{\mathrm{Se}_{4} \cdot 2 \mathrm{H}_{2} \mathrm{O}+} \\
\text { byproducts. }
\end{array}
$$

\section{Results and discussion}

The SeMgHPO ${ }_{4}$ crystals are grown in three different growth faces by applying various growth parameters. Figures 1-3 represent three different growth columns, respectively. Table 1 gives the growth parameters of $\mathrm{SeMgHPO}_{4}$ crystals and the bold letters show the optimum growth para- 
meters. Among them, the laser exposed (semiconductor diode laser source, wavelength of laser is $7300 \AA, 20 \mathrm{~mW}$ laser power passed continuously with using SMPS power supply) growth medium shows better nucleation reduction and no crystals were formed, because of the inability to attain supersaturation as shown in figure 4. In sun light exposed medium partial nucleation was observed, since exposure of sunlight to the growth medium was (During sunlight exposure, the kinetic energy of growth solution increases since it was unable to attain continuous supersaturation) only in day time i.e. $8 \mathrm{~h}$ per day and the growth column is as shown in figure 3 , growth period was seven months.

\subsection{FTIR spectral analysis of SeMHP crystal}

SeMHP-FTIR spectrum was recorded by using SHIMADZU FTIR-435 instrument. The FTIR spectrometer has $\mathrm{KBr}$ pellets sample holder and $\mathrm{KBr}$ detector. The $\mathrm{KBr}$ pellet

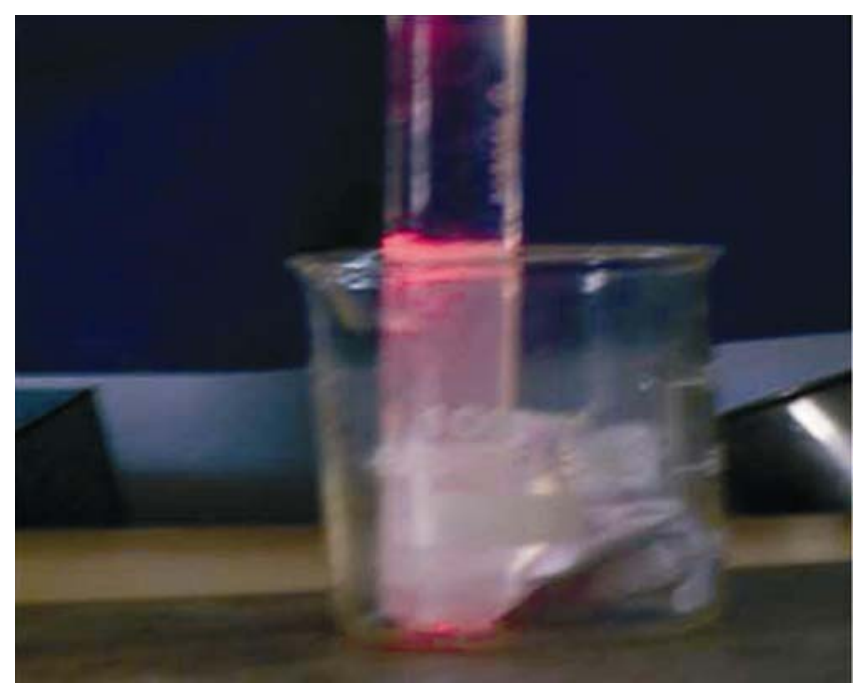

Figure 3. Growth of SeMHP crystal within laser exposed medium in SDP.

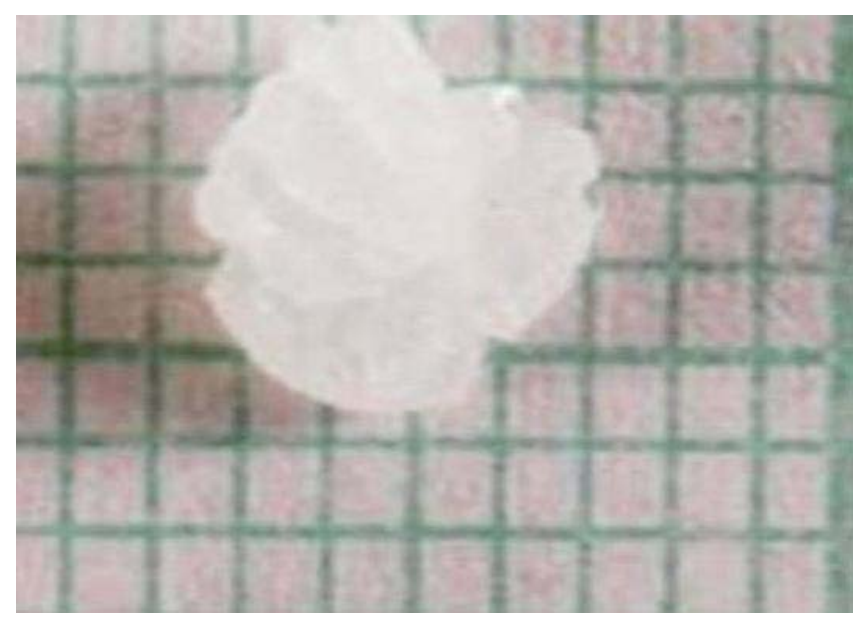

Figure 4. Harvested SeMHP crystal in SDP. samples were used and the absorption frequencies range from $600-4000 \mathrm{~cm}^{-1}$. The FTIR spectrum is as shown in figure 6 . The spectrum was interpreted with the earlier reported values (Yean et al 1961; Corns 1983). The absorption bonds, absorption frequencies and \% of transmittance were compared with the reported values. The values are tabulated in table 2 .

\subsection{Thermogravimetric (TGA and DTA) analysis of SeMHP crystal}

The TGA and DTA of SeMHP crystals were carried out by STA 11500-PLTS instruments. The MHP crystal of $5.487 \mathrm{mg}$ sample was taken to the TGA process. The TGA was started from room temperature to $900^{\circ} \mathrm{C}$ by heating at a constant rate. Figure 7 shows the TGA and DTA graph of SeMHP crystals (Sundaramoorthi et al 2007a, b). The $\%$ of weights present in the SeMHP sample at a particular temperature was tabulated in table 3 .

\subsection{Etching study of SeMHP crystal}

A well-grown SeMHP crystal was immersed in $\mathrm{HCl}$ solution at a desired concentration. The dissolution of SeMHP crystal depends upon the etchant concentration, temperature, crystal morphology, etching time etc. The etch pits were photographed. Figure 8 shows the etch pits of SeMHP crystal (Gilman et al 1956, 1958; New Kirk 1962). The etch pit patterns are observed in spirals, dendrites, vallies and strights.

\subsection{Scanning electron microscopic studies of SeMHP crystal}

A well-grown SeMHP single crystal was selected for the investigation of surface morphology of the grown crystal

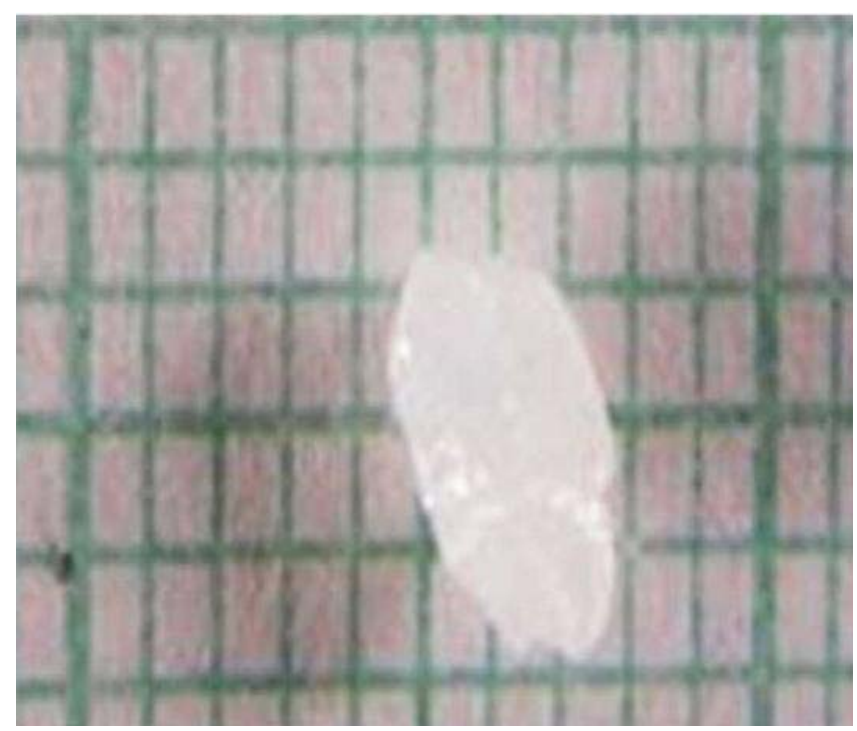

Figure 5. Harvested SeMHP crystal in SDP. 
Table 2. Comparative table of FTIR-SeMHP crystal.

\begin{tabular}{|c|c|c|c|c|}
\hline Sl. no. & Bonds/vibrations & Reported values $\left(\mathrm{cm}^{-1}\right)$ & Observed values $\left(\mathrm{cm}^{-1}\right)$ & $\%$ of Transmittance \\
\hline 01 & $\begin{array}{l}\text { Symmetric and asymmetric } \\
\text { stretching } \mathrm{O}-\mathrm{H} \text { bond }\end{array}$ & 3284 & $3267 \cdot 2$ & 6 \\
\hline 02 & $\mathrm{H}-\mathrm{O}-\mathrm{H}$ bond & 1651 & $1608 \cdot 5$ & 16 \\
\hline 03 & Alkyle symmetric stretching & $2852 \cdot 3$ & $2852 \cdot 2$ & $13 \cdot 6$ \\
\hline 04 & $\mathrm{P}-\mathrm{O}-\mathrm{P}$ asymmetric stretching bond & 874 & $898 \cdot 8$ & 13 \\
\hline \multirow[t]{2}{*}{05} & $\mathrm{PO}_{4}$ bond & 1000 to 1100 & $1020 \cdot 3$ & $3 \cdot 8$ \\
\hline & & & $1064 \cdot 6$ & $4 \cdot 8$ \\
\hline 06 & Weak absorption of $\mathrm{HPO}_{4}^{2-}$ & 2375 & $2345 \cdot 3$ & 17 \\
\hline 07 & Alkyle asymmetric stretching & $1465 \cdot 3$ & $1508 \cdot 2$ & 15 \\
\hline 08 & $\mathrm{Se}, \mathrm{Mg}-\mathrm{H}$ in plane stretching & $1240 \cdot 1$ & $1240 \cdot 1$ & 10 \\
\hline 09 & $\mathrm{P}=\mathrm{O}$ stretching & 1137 & $1168 \cdot 8$ & $5 \cdot 6$ \\
\hline 10 & Acid phosphate strong absorption & 525 & $507 \cdot 2$ & 7 \\
\hline
\end{tabular}

Table 3. Thermal decomposition of SeMHP crystal.

\begin{tabular}{lccc}
\hline & \multicolumn{3}{c}{ TGA } \\
\cline { 2 - 3 } Points & Temperature $\left({ }^{\circ} \mathrm{C}\right)$ & \% of SeMHP crystal present & DTA $\left({ }^{\circ} \mathrm{C}\right)$ \\
\hline 1 & 30 & 100 & 128.47 \\
2 & 131.60 & 101.240 & 182.53 \\
3 & 199.76 & 74.948 & 249.77 \\
4 & 452.24 & 67.941 & 669.10 \\
5 & - & - & 691.28 \\
\hline
\end{tabular}

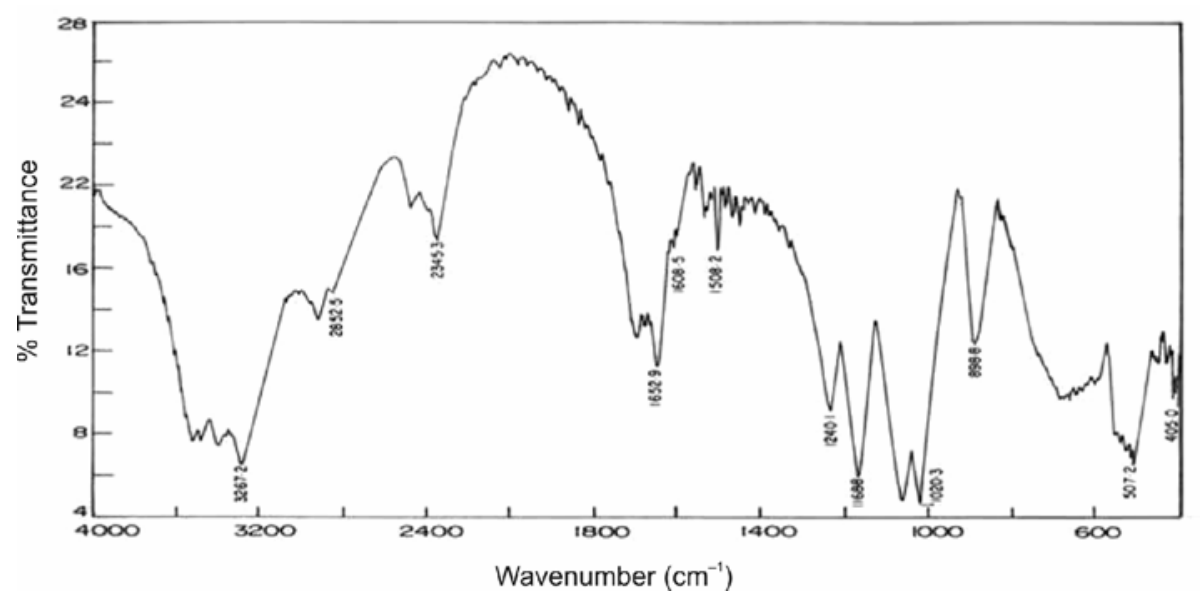

Figure 6. FTIR spectrum of SeMHP crystal.

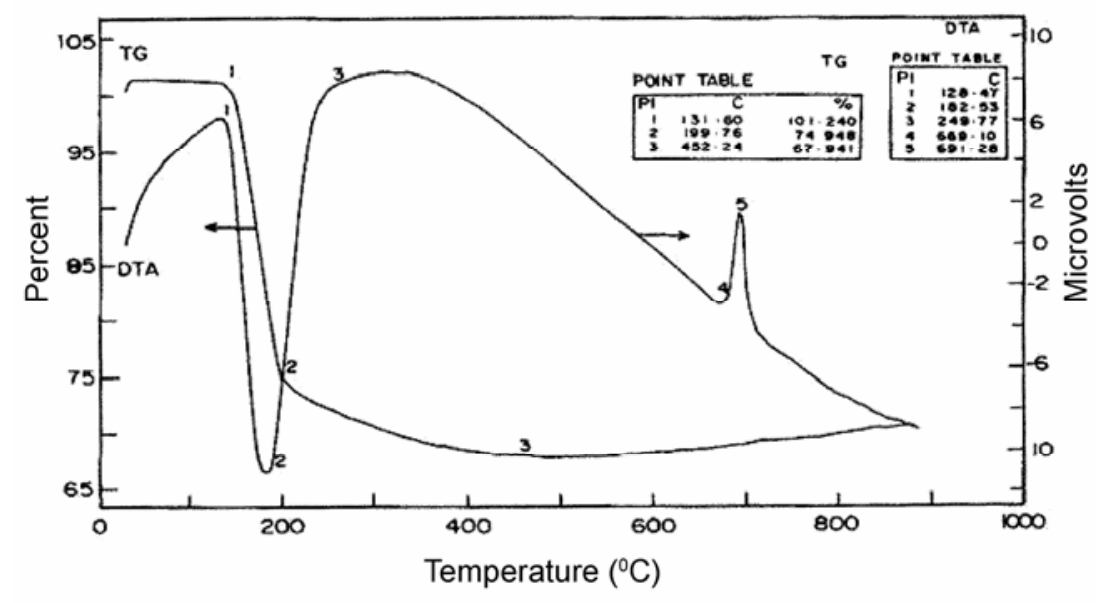

Figure 7. Thermogravimetric (TGA and DTA) analysis of SeMHP crystal. 
by using SEM. The SEM photograph was obtained in the version S-300-I instrument. The sample named as VCA600 was kept in lobe middle; the data size was $640 \times$ $480 \mu \mathrm{m}$. The minor and major magnifications of SEM were about 250 times. SEM acceleration voltage was $25000 \mathrm{~V}$ and the sample was kept in a highly vacuum state. 18200 micrometer work distance was maintained and monochromatic colour mode was employed. Figure 9 shows the SEM pattern and surface morphologies of SeMHP crystal (Gates 1975; Taukamot 1983; Bethage et al 1987; Albon et al 1996; Sundaramoorthi 2007a, b).

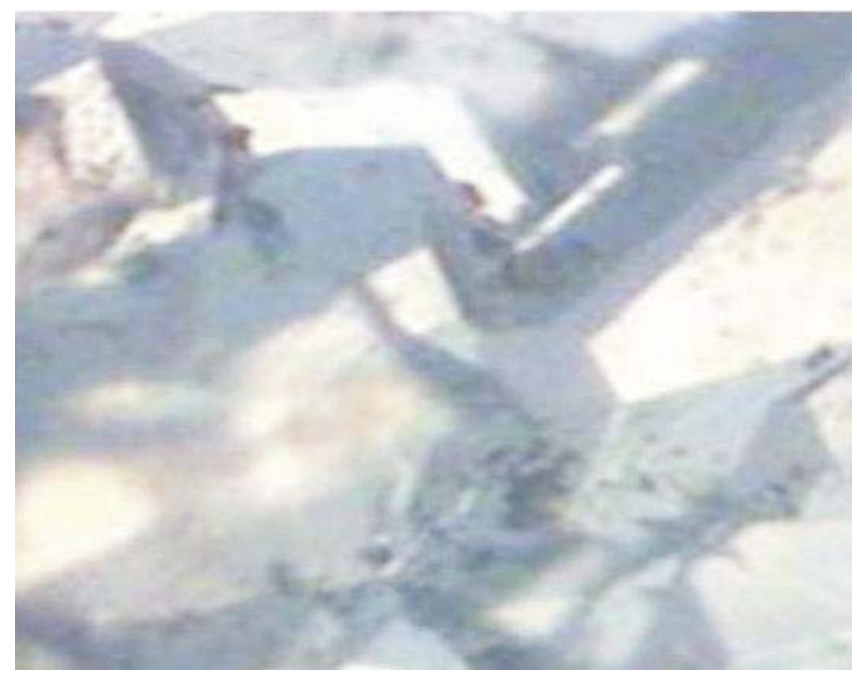

Figure 8. Shows the etch pit pattern of SeMHP crystal [at $1 \mathrm{~N}$ normality] of $\mathrm{HCl}$ solution as etchant, the etching time was $5 \mathrm{~min}$ in room temperature.

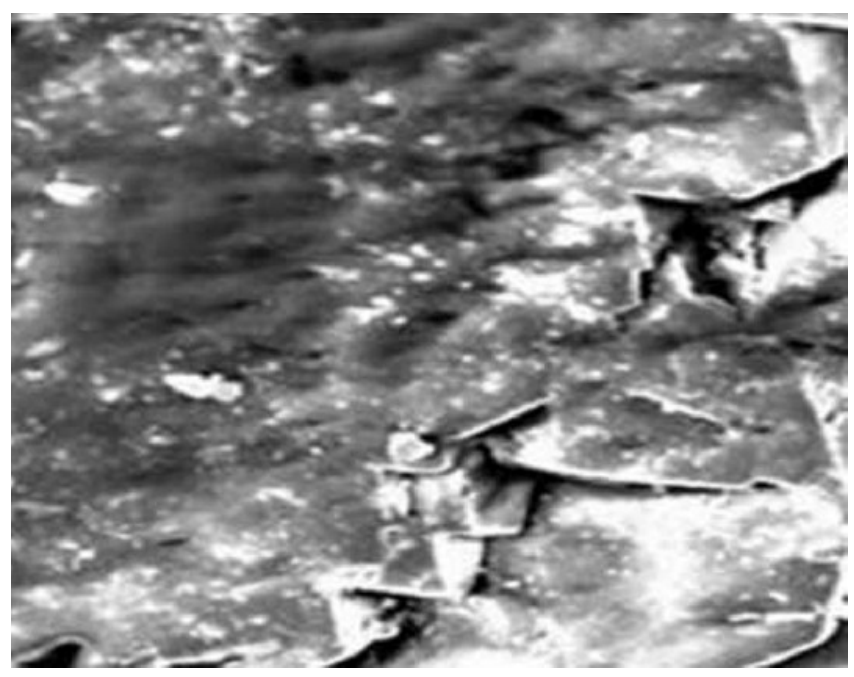

Figure 9. SEM photograph of SeMHP crystal.

\section{Conclusions}

The SeMHP crystals were grown at room temperature and exposed to sunlight and laser medium. It was found that SeMHP crystal nucleation rate was reduced fully in laser exposed medium than the sunlight-exposed medium, which is due to variation of supersaturation (low power laser light may apply through endoscope cable via the exposed urinary tract to avoid renal stones). FTIR spectrum recorded the functional frequencies of SeMHP crystal constituents. These results were recorded and compared with the reported values. Chemical etching was done at room temperature, which revealed the grown crystal defects. SEM analysis was also done to analyse the surface morphology of SeMHP crystal. The decomposition temperature and percentage of weight loss of the grown crystal was recorded by TGA and DTA spectrum.

\section{References}

Albon N et al 1996 in Growth and perfection of crystals (New York: Wiley) p. 44

Alexander A E and Honson P 1949 Colloid science (Oxford: Clarendon Press)

Arthure H and Obst J 1953 Gym. Br. Emp. 60416

Bethage $\mathrm{H}$ et al 1987 Electron microscopy in solid state physics (Amsterdam: Elsevier)

Corns C M 1983 Ann. Clin. Bio-Chem. 2020

Dieppe P and Calver P 1986 Crystals and joint diseases (London: Chapman and Hall)

Eitel W 1954 in Physical chemistry of silicate (Chicago: University of Chicago Press)

Fisher J C 1957 in Dissolutions and mechanical properties of crystals (New York: John Wiley)

Gates H C 1975 Thirty years of progress in surface science, in Crystal growth and characterization (North Holland)

Gilman J J et al 1956 J. Appl. Phys. 271018

Gilman J J, Johnson J and Sears G W 1958 J. Appl. Phys. 29749

Henisch H K et al 1965 J. Electrochem. Soc. 112627

Henisch H K 1988 Crystal growth in gels and Liesegang rings (Cambridge: Cambridge Univ. Press)

Hess B and Kok D J 1996 Nucleation, growth and aggregation of stone forming crystals in kidney stones-medical and surgical management (eds) F L Coe et al (Philadelphia: Lippincot Raven) p. 3

New Kirk J B 1962 in Direct observation of imperfection in crystals (New York: Interscience Publishers)

Sundaramoorthi P and Kalainathan S 2007a Asian J. Chem. 19 2783, 3739

Sundaramoorthi P and Kalainathan S 2007b J. Bio. Chem. Engg. 34244

Sutor D J 1989 The nature of urinary stones and their analysis in renal tract stone - Metabolic basic and clinical practice (eds) J B A Wicktham and A C Buck (Edinburgh: Churchill Livingstone) p. 29

Taukamot K 1983 J. Cryst. Growth 6199

Yean Chin Tasai et al 1961 J. Urol. 86838 